\title{
Bovine herpesviruses induce different cell death forms in neuronal and glial-derived tumor cell cultures
}

\author{
Tereza C. Cardoso ${ }^{1}$ - Ana Carolina G. Rosa ${ }^{1}$ Helena L. Ferreira ${ }^{1,2}$. \\ Lucas H. Okamura $^{1}$ - Bruna R. S. M. Oliveira ${ }^{1}$ - Flavia V. Vieira ${ }^{1}$. \\ Camila Silva-Frade $^{1} \cdot$ Roberto Gameiro $^{1} \cdot$ Eduardo F. Flores $^{3}$
}

Received: 29 September 2015 /Revised: 29 March 2016 / Accepted: 4 April 2016 /Published online: 16 June 2016

(C) Journal of NeuroVirology, Inc. 2016

\begin{abstract}
Oncolytic viruses have the ability to infect tumor cells and leave healthy cells intact. In this study, bovine herpesvirus 1 (BHV1; Los Angeles, Cooper, and SV56/90 strains) and bovine herpesvirus 5 (BHV5; SV507/99 and GU9457818 strains) were used to infect two neuronal tumor cell lineages: neuro2a (mouse neuroblastoma cells) and C6 (rat glial cells). BHV1 and BHV5 strains infected both cell lines and positively correlated with viral antigen detection $(p<0.005)$. When neuro2a cells were infected by Los Angeles, SV507/99, and GU9457818 strains, $40 \%$ of infected cells were under early apoptosis and necroptosis pathways. Infected C6 cells were $>40 \%$ in necroptosis phase when infected by BHV5 (GU9457818 strain). Blocking caspase activation did not interfere with cell death. However, when necroptosis was blocked, $60-80 \%$ of both infected cells with either virus switched to early apoptosis pathway with no interference with virus replication. Moreover, reactive oxygen species production and mitochondrial membrane dysfunction were detected at high levels in both infected cell lines. In spite of apoptosis and necroptosis blockage, tumor necrosis factor alpha (TNFA) and virus transcription were positively correlated for all viral strains studied. Thus, these results contribute to
\end{abstract}

Tereza C. Cardoso

tcardoso@fmva.unesp.br

1 DAPSA Department, Laboratory of Animal Virology and Cell Culture, College of Veterinary Medicine, Universidade Estadual Paulista, Araçatuba, São Paulo 16050-680, Brazil

2 FZEA-USP, Departamento de Medicina Veterinária, Av. Duque de Caxias Norte, 225, Pirassununga, SP CEP 13635-900, Brazil

3 Virology Section, Federal University of Santa Maria, Santa Maria 97115-900, RS, Brazil the characterization of BHV1 and BHV5 as potential oncolytic viruses for non-human cells. Nonetheless, the mechanisms underlying their oncolytic activity in human cells are still to be determined.

Keywords Oncolytic viruses - Animal herpesvirus · Apoptosis $\cdot$ Necroptosis $\cdot$ Oxidative stress $\cdot$ Pathogenesis

\section{Introduction}

Bovine herpesvirus 1 and 5 (BHV1 and BHV5, respectively) belong to the family Herpesviridae, subfamily Alphaherpesvirinae, genus Varicellovirus (Davison et al. 2009; Davison 2010). BHV1 has been incriminated to induce respiratory and genital disorders whereas BHV5 is the agent of meningoencephalitis (Del Médico Zajac et al. 2010). Oncolytic viruses are defined for their ability to replicate in neoplasic cells and, somehow, to produce their destruction (Cuddington and Mossman 2015). In this respect, BHV1 has been used to infect and destroy human neoplasic cells derived from a variety of mesenchymal and/or epithelial origin (Cuddington and Mossman 2015). Interestingly, BHV1 seems not to infect or cause cytotoxic effect in non-neoplasic human cells (Cuddington and Mossman 2015). Moreover, equine herpesvirus type 1 (EHV-1), another alphaherpesvirus, has been shown to infect human glioblastoma multiforme cells (Courchesne et al. 2011; Cuddington and Mossman 2014).

Programmed cell death or apoptosis is a physiological mechanism implicated, in some cases, in eliminating viral infections (Hay and Kannourakis 2002; Griffin et al. 2010). In contrast, viruses may manipulate anti-apoptotic signals aimed to control/inhibit cell death and, as a consequence, to allow virus replication to proceed (Ohta and Nishiyama 2011). Apoptosis may be activated through two pathways: intrinsic 
and extrinsic (Hay and Kannourakis 2002). The intrinsic pathway is characterized by induction of cell stress that activates molecules on the mitochondria surface (Elmore 2007; Scott 2010; Ohnishi et al. 2013; West et al. 2011). The extrinsic apoptotic pathway can be activated by a variety of external stimuli, known as cytokines, toxins, or modulation of cell surface receptors classified as death receptors: tumor necrosis factor (TNF), Fas ligand (FasL), and TNF-related apoptosisinducing ligand (Griffin et al. 2010; Dashzeveg and Yoshida 2015; Elmore 2007; Probert 2015).

TNF alpha (TNF- $\alpha$; TNFA) is an inflammatory cascade inducer classified as a pro-inflammatory cytokine (Dashzeveg and Yoshida 2015). This cytokine is important in the innate immunity and crucial against viral infections (Probert 2015). After viral infection, TNF- $\alpha$ production results in fever, cell death, and cachexia and stimulates the inflammatory process (Elmore 2007). In special cases, TNF- $\alpha$ also produces tumorigenesis inhibition and blocks viral replication (Probert 2015) by activation of the caspase cascade, which activates cell apoptosis (Elmore 2007). Necroptosis is a regulated form of primary necrosis that does not involve caspase activation (Silke et al. 2015). Apoptosis and necroptosis mechanisms are rather interconnected and not entirely independent (Silke et al. 2015). To reinforce this, a study demonstrated that $F A S$ or $T N F$ genes, which normally activate apoptosis through death receptors, can induce necroptosis when caspases are inhibited or deficient, in different susceptible cell lines (Probert 2015; Silke et al. 2015). Although apoptotic mechanisms during viral infections have been well studied, necroptosis remains largely unclear.

In response to pathogens, the innate immune responses recruit and activate phagocytic macrophages, neutrophils, and, during neuronal infections, resident microglia cells (Gonzalez-Dosal et al. 2012). These immune cells eliminate invading pathogens by the production of reactive oxygen species (ROS) (Englezou et al. 2012; Kulahava et al. 2010). ROS production may be either beneficial or harmful to host cells, yet its generation is part of the host immune response against invading microorganisms (Kulahava et al. 2010). In this sense, rabbit brains infected with BHV5 displayed nitric oxide (NO) overproduction, which correlated to virus dissemination (Dezengrini et al. 2009). In mammals, when NO is produced with ROS, it also displays neurotoxicity and may induce apoptotic cell death in different neuronal cell types (Ohnishi et al. 2013). As described, the potential of animal alphaherpesviruses to infect neuronal and glial-derived tumor cells is not fully understood. In this study, we investigated the susceptibility of tumor neuronal and glial cells to BHV1 and BHV5 strains, in order to investigate the potential oncolytic properties of these viruses. For this purpose, apoptosis and/or necroptosis associated with virus infection were investigated. Moreover, the characterization of cell death, TNFA transcription, and ROS production were also examined.

\section{Materials and methods}

\section{Cell culture, viruses, and infection}

Neuro2a (mouse neuroblastoma, ATCC \# CCL131) and C6 (rat glial cell tumor; ATCC \# CCL107) were used in the experiments. Cells were seeded in $25 \mathrm{~cm}^{2}$ flasks and 96-culture plates to perform growth curve/viability and virus titration (Nunc ${ }^{\mathrm{TM}}$, Rochester, NY, USA). Cell culture conditions have been previously described (Cardoso et al. 2015). BHV1 strains (Los Angeles, Cooper, and SV56/90) (Weiblen et al. 1992; Cardoso et al. 2015) and BHV5 strains (SV507/99 and GU9457818) (Delhon et al. 2003; Ferrari et al. 2007) were used.

Cells were inoculated with BHV suspensions $\left(10^{2.7}\right.$ $\mathrm{TCID}_{50} / \mathrm{ml}$ ) according to previous study (Cardoso et al. 2015). Briefly, viral suspensions were allowed to adsorb for $1 \mathrm{~h}$ at $38.5^{\circ} \mathrm{C}$, and following inoculation, infected and uninfected cells were visualized under phase-contrast microscopy for cytopathic effect. For one-step growth assays, cells $\left(5 \times 10^{5}\right.$ per well $)$ were seeded into 96 -well plates in duplicate and inoculated with the viruses as described (Cardoso et al. 2015). After $2 \mathrm{~h}$ of adsorption, the inoculum was removed and cells were washed twice with medium and further incubated at $37^{\circ} \mathrm{C}$. At $24,48,72,96$, and $120 \mathrm{~h}$ post-infection (p.i), supernatants and cell-associated virus were recovered and stored at $-86{ }^{\circ} \mathrm{C}$. The $50 \%$ tissue culture infectious dose $\left(\mathrm{TCID}_{50}\right)$ of the samples was determined by limited dilution and the data log transformed (Cardoso et al. 2015).

\section{Immunocytochemistry}

Immunocytochemistry was performed according to previous study with some modifications (Cardoso et al. 2015). Briefly, infected and control Neuro2a and C6 cells were fixed at $48 \mathrm{~h}$ p.i with $4 \%$ paraformaldehyde for $15 \mathrm{~min}$ followed by incubation overnight at $4{ }^{\circ} \mathrm{C}$ with monoclonal antibodies to BHV1 (MAb 7F12) and BHV5 (2F9 and 1F3) (Varela et al. 2010; Oldoni et al. 2004). After three washes, cells were incubated with the respective goat secondary antibody $(1: 100)$ anti-mouse FITC (Sigma-Aldrich ${ }^{\circledR}$ ) and nuclear staining was performed with $1 \mathrm{mg} / \mathrm{ml}$ of DAPI (4'-6-diamino-2phenylindole; Sigma-Aldrich ${ }^{\circledR}$ ) and $0.1 \mathrm{mg} / \mathrm{ml}$ of propidium iodide (PI) was diluted in Fluormount ${ }^{\mathrm{TM}}$ aqueous medium. The images were collected under an AxioImager ${ }^{\circledR}$ A.1 light and an ultraviolet (UV) microscope connected to an AxioCam ${ }^{\circledR M R c}$ (Carl Zeiss, Oberkochen, Germany). The images were processed using AxioVision ${ }^{\circledR} 4.8$ software (Carl Zeiss) for viral antigen detection. Ten fields were analyzed in each condition, and photographs were taken at $\times 200$ magnification by AxioVision ${ }^{\mathrm{TM}}$ software (Olympus). 


\section{Induction of apoptosis/necroptosis and production of ROS}

In order to evaluate apoptosis and production of ROS, $1 \times 10^{6}$ cells $/ \mathrm{ml}$ were infected with $10^{2.7} \mathrm{TCID}_{50} / \mathrm{ml}$ of each virus strain. In parallel, cells were treated with $1.5 \mu \mathrm{M}$ of staurosporine (Sigma-Aldrich ${ }^{\circledR}$ ) for $6 \mathrm{~h}$ to induce apoptosis, as positive control (Cardoso et al. 2015). In another two experiments, both cell lines were pre-treated with $4 \mu \mathrm{M}$ pancaspase inhibitor z-vad-fmk (Sigma-Aldrich $®$ ); after $1 \mathrm{~h}$, BHV infection was performed. As control, cells were exposed only to pan-caspase inhibitor. In order to evaluate necroptosis, inhibition of receptor-interacting protein kinase was induced with $1 \mu \mathrm{M}$ of necrostatin 1 (nec-1; cat \# N9037, SigmaAldrich $\left.{ }^{\circledR}\right)$. After treatment, BHV strains were inoculated into cell cultures and monitored. The ROS-positive control was composed by cells exposed to $5 \%$ of $\mathrm{CO}_{2}$ atmosphere during $30 \mathrm{~min}$.

\section{Flow cytometric analysis of apoptosis/necroptosis, ROS production, and mitochondrial membrane potential}

The flow cytometric analysis of apoptosis/necroptosis, ROS production, and mitochondrial membrane potential were acquired via an Attune ${ }^{\mathrm{TM}}$ acoustic focusing cytometer system at $48 \mathrm{~h}$ after virus inoculation (Applied Biosystems ${ }^{\circledR}$, Foster City, CA, USA) with parameters established in a previous study (Cardoso et al. 2015). Apoptosis/necroptosis was measured using double-staining method with The Vybrant Apoptosis Assay Kit (Molecular Probes ${ }^{\mathrm{TM}}$, Life Technologies ( $)$ and APO-BrdUTM TUNEL assay Kit (Molecular Probes ${ }^{\mathrm{TM}}$, Life Technologies) according to previous study (Cardoso et al. 2015). The differentiation of early apoptotic, secondary necrotic, necroptotic, and viable cells was made according to their phenotype: BrdU +/PI-were considered early apoptotic, BrdU-/PI+ necroptotic, BrdU+/PI+ secondary necrotic, and BrdU-/PI- viable cells. Data were acquired following the Attune equipment parameters described previously (Cardoso et al. 2015). The results were expressed as $\Delta \%$ of each cell phenotype.

The ROS production was measured by Fluorometric Intracellular ROS ${ }^{\text {TM }}$ kit (cat \# MAK142, Sigma-Aldrich ${ }^{\circledR}$ ) according to manufacturer's instructions. Briefly, $1 \times 10^{6}$ cells $/ \mathrm{ml}$ were centrifuged, and the resulted pellet was mixed in $40 \mu \mathrm{l}$ of ROS detection reagent solution. After, data from cells exposed to all experiments were captured.

To perform the mitochondrial membrane potential assay, $2 \times 10^{3}$ infected and uninfected cells were incubated with $10 \mu \mathrm{g} / \mathrm{ml}$ of JC-1 $\left(5,5^{\prime}, 6,6^{\prime \prime}\right.$-tetrachloro-1, $1^{\prime}, 3,3^{\prime}$ tetrathylbenzimidazolyl-carbocyamine iodide; Molecular Probes ${ }^{\mathrm{TM}}$, Eugene, OR) for $10 \mathrm{~min}$ at $37^{\circ} \mathrm{C}$ and analyzed by acoustic flow cytometry in the dark according to previous study (Cardoso et al. 2015).

\section{Molecular quantification}

Infected and control cell lines were submitted to DNA extraction at $48 \mathrm{~h}$ pi using DNAzol ${ }^{\mathrm{TM}}$ according to manufacturer's instructions (Invitrogen $\left.{ }^{\circledR}\right)$. SYBR-Green fluorescence assay-based real-time PCR was used in a total of $100 \mathrm{ng}$ of genomic DNA as described previously (Cardoso et al. 2013). The primers used were: BHV1 forward 5'-GGTACATGTCCAGGGAAAC-3'; BHV1 reverse 5'- GGTACAACATCGTCAACTTC-3' BHV5 forward 5'-GGTACTTCTTCTTGGTGATG-3'; BoHV5 reverse 5'-TCGGTCTTCGTCAAGTTC-3' (H2A): forward 5'GTCTTGGAGTACCTGACCGC-3'; reverse 5' ACAACGAGGGCTTCTTCTGA- $3^{\prime}$ as described previously (Diallo et al. 2011; Silva-Frade et al. 2014).

Total RNA was extracted from cell monolayers using Trizol TM protocol according to manufacturer's instructions (Invitrogen $($ ). An average of 100 ng of RNA treated with DNase was used for qPCR in order to quantify TNFA gene (Bt03259156_m1). The primers and respective probes used were purchased from Applied Biosystems customer service.

The reactions were carried out and analyzed by the software on a StepOnePlus ${ }^{\mathrm{TM}}$ real-time instrument (Applied Biosystems $\left.{ }^{\circledR}\right)$. The data were obtained from three replicates of each sample. The expression of the housekeeping Histone 2a gene was also quantified in a similar way for normalization as described previously (Silva-Frade et al. 2014). The comparative delta-delta $\mathrm{C} t$ method was used to analyze the results (Cardoso et al. 2013).

\section{Statistical analysis}

All experiments were performed at least in duplicate. Descriptive statistics include the mean \pm standard deviation (s.d.). A $p$ value $<0.005$ was considered significant. All statistical analyses were performed using Prism software (GraphPad® v.6, CA, USA). Gene expression values were transformed in logs, and correlations were evaluated with Spearman correlation coefficient. The differences between various groups were examined for a significance using the non-parametric Mann-Whitney $U$ test.

\section{Results}

\section{BHV1 and BHV5 replication on Neuro2a and C6 cells}

The first experiments were conducted to characterize the replication of BHV1 and 5 strains in the cell lines and their induced cytopathic effects. Virus replication produced floating rounded cells and disruption of the cell monolayer in all BHV strains studied (data not shown). The graphic revealed a peak of virus titers at $48 \mathrm{~h}$ p.i. for all BHV strains in both cell lines (Fig. 1a, b). Virus antigen was detected by 


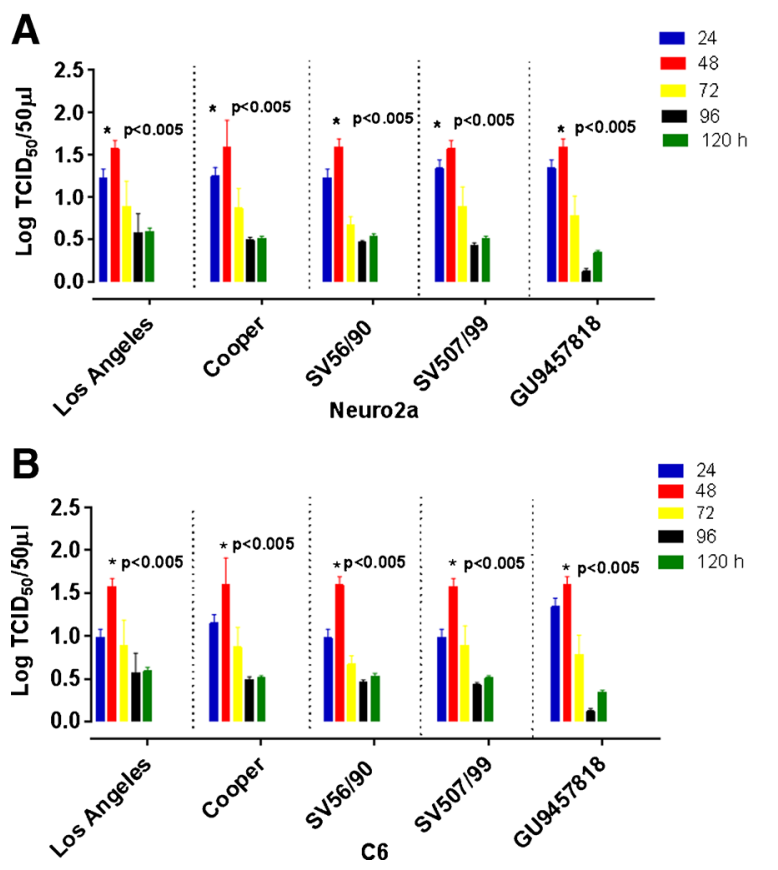

Fig 1 Evaluation of BHV1 and BHV5 titers at different times after infection. a Neuro2a and b C6 cells both infected with BHV strains $(p<0.005)$. The data were $\log$ transformed corresponded to tissue culture infectious dose $50 \%$ method $(p<0.005)$. c Analysis of BHV

immunocytochemistry and confirmed virus replication, as shown by a representative photomicrograph for both cell lines infected by BHV strains at $48 \mathrm{~h}$ p.i. (Fig. 1c). A significant correlation was detected $(r=0.878)$ between virus titers and immunostaining $(p<0.005)$.

\section{Determination of apoptosis and necroptosis}

To investigate whether apoptosis occurred in the process of virus-induced neuronal death, TUNEL assay was applied at $48 \mathrm{~h}$ p.i. In an experiment in which Neuro2a cells were infected by Los Angeles, SV507/99 (BHV5 reference strain), and GU9457818 (BHV5, field isolate), early apoptosis and necroptosis reached the same levels, $\approx 40 \%$ at $48 \mathrm{~h}$ p.i. (Fig. 2a). Cooper and SV56/90 infection in the same cells produced lower levels of early apoptosis, followed by increase of viable cells (Fig. 2a). The results observed in C6 cells infected by BHV strains revealed a decrease of early apoptosis followed by an increase of viable cells, except for GU9457818 (BHV5, field isolate) that produced $>40 \%$ of necroptotic cells. Likewise, no differences in early apoptosis/necroptosis rates were observed when a pan-caspase inhibitor was applied (data not shown). However, when nec-1 (an inhibitor of necroptosis) was applied, a significant increase of cells under early apoptosis was observed for both infected cells (60$80 \%$ ) and all BHV strains (Fig. 3a, b). In summary, these

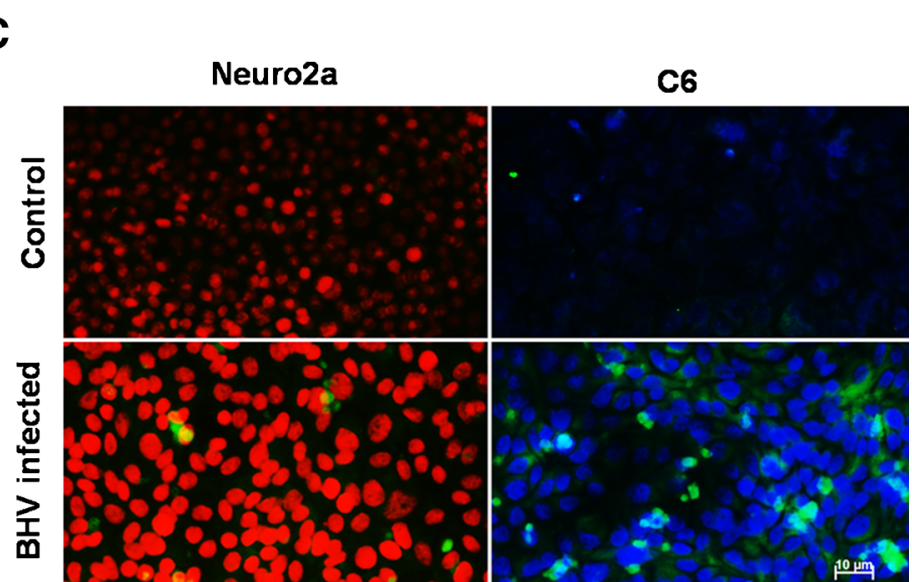

antigens by immunocytochemistry performed using monoclonal antibodies against BHV1 and 5 (green) followed by PI (red) and DAPI (blue) counterstain. The photomicrography is representative for all BHV strains used. $\times 40$ magnification

results showed that BHV strains replication directly affect cell metabolism during early apoptosis phase in both tumor cells.

\section{ROS production and mitochondria membrane depolarization}

In both cell lines, BHV1 and 5 infection leads to ROS production (Fig. 4a, b). However, Los Angeles and SV56/90 strains induced 76.89 and $86.07 \%$ Neuro2a cells to oxidative stress at $48 \mathrm{~h}$ p.i. (Fig. $4 \mathrm{~b}$ ). Cooper, SV507/99, and GU9457818 strains induced 71.05, 76.10, and $91.03 \%$ cells to produce ROS (Fig. 4b). The JC-1 probe emission is illustrated (Fig. 5a, b). All BHV strains produced mitochondrial membrane depolarization at 48 h p.i.; however, Cooper strain revealed the lowest level of cells under mitochondrial damage when Neuro2a cells were infected (Fig. 5a). The BHV5 strains, SV507/99 and GU9457818, produced the highest mitochondria membrane depolarization $(p<0.005)$ compared to BHV1 strains for infected Neuro2a cells (Fig. 5a). Los Angeles strain produced the lowest level mitochondria membrane depolarization in comparison to other BHV1 and BHV5 strains in C6infected cells (Fig. 5b). Overall, replication of BHV strains in both tumor cell lines was able to activate the oxidative stress pathway to different degrees. 
Fig. 2 Percentage of early apoptosis/necroptosis-positive cells after $48 \mathrm{~h}$ p.i with BHV1 and BHV5 strains, Neuro2a (a) and C6 (b) cells; $* p<0.005$. Negative control corresponded to uninfected cells at the same p.i. Positive control corresponded to both cells submitted to $1.5 \mu \mathrm{M}$ of staurosporine at $48 \mathrm{~h}$ p.i
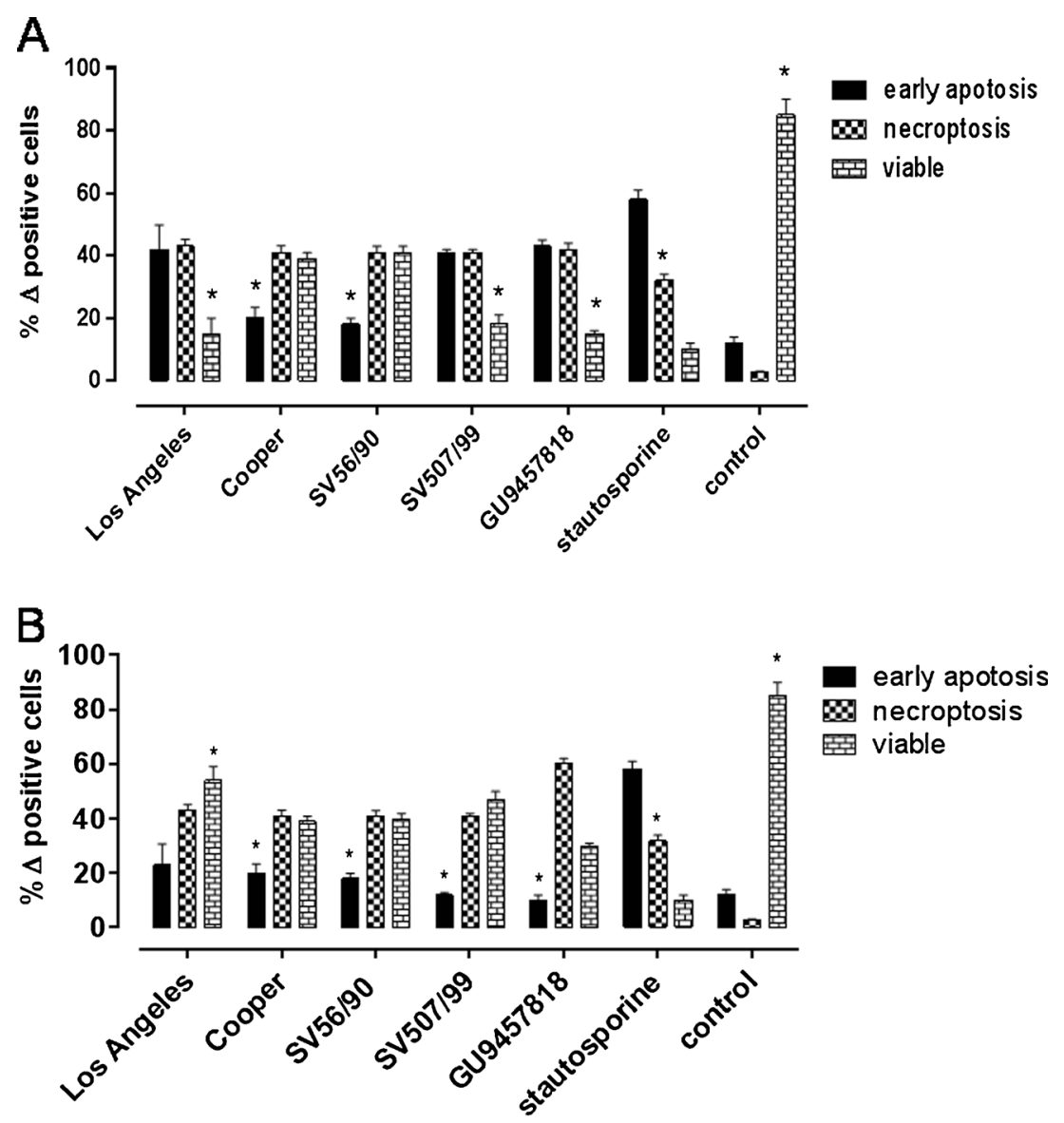

\section{TNFA expression after BHV infection}

The expression of TNFA and BHV glycol-C genes was determined at $48 \mathrm{~h}$ p.i., and a positive correlation was found when Neuro2a and C6 cells were infected by SV56/90 and GU9457818 strains, respectively (Figs. 6 and 7). However, TNFA and BHV glycol-C gene expression was considered positively correlated for all analyses (Figs. 6 and 7). In spite of apoptosis and necroptosis block, no interference could be observed in the expression of TNFA and BHV glycol-C during infection on both tumor cell lines. Taken together, these results show that BHV replication in both cell lines activated TNFA transcription with no interference on virus production.

\section{Discussion}

The current study pioneered to demonstrate that animal herpesviruses, e.g., BHV, are capable to infect and produce damage in non-human glioma lineage cells, with production of mitochondrial membrane depolarization and ROS production. Numerous viruses have developed different mechanisms to overcome infected hosts defense (Elmore 2007; Geiser et al. 2008). Apoptosis is a cell programmed suicide mechanism essential for development in all metazoan animals (Hay and Kannourakis 2002). In some situations, viruses may take advantages of inducing apoptosis: either to perform the infected cells death, facilitating virus dissemination, or to destroy immune system cells (Egan et al. 2013; Hood et al. 2003; Schachtele et al. 2010).

Most of alphaherpesviruses have been shown to induce cell destruction caused by apoptosis (Christensen et al. 2011; Cymerys et al. 2012; Delhon et al. 2002; Geiser et al. 2008; Hood et al. 2003; Montagnaro et al. 2013). Although different apoptotic forms have been described induced by BHV1 and 5 infection (Brenner et al. 2012; Cardoso et al. 2012, 2015; Delhon et al. 2002; Garcia et al. 2013; Geiser et al. 2008; Ladelfa et al. 2013; Silva-Frade et al. 2010, 2014; Zhu et al. 2016), this particular mechanism remains unknown. Likewise, only few reports describe the susceptibility of human tumor cells to BHV1 (Cuddington and Mossman 2014). In this sense, our results demonstrated the ability of BHV1 and 5 to infect neuronal tumor cells with different rates of apoptosis and/or necroptosis. In fact, the cytopathic effect revealed a cytolysis fairly different to what has been demonstrated for neuron-like cells, whereas Cooper strain (BHV1) did not produce complete cell lysis (Cardoso et al. 2015). In 
Fig. 3 Percentage of early apoptosis/necroptosis positive cells after $48 \mathrm{~h} \mathrm{p}$.i, pre-treated with nec-1 and after infected with BHV1 and BHV5 strains, Neuro2a (a) and C6 (b) cells; $* p<0.005$. Negative control corresponded to uninfected cells at the same p.i. Positive control corresponded to both cells submitted to $1.5 \mu \mathrm{M}$ of staurosporine at $48 \mathrm{~h} \mathrm{p.i}$
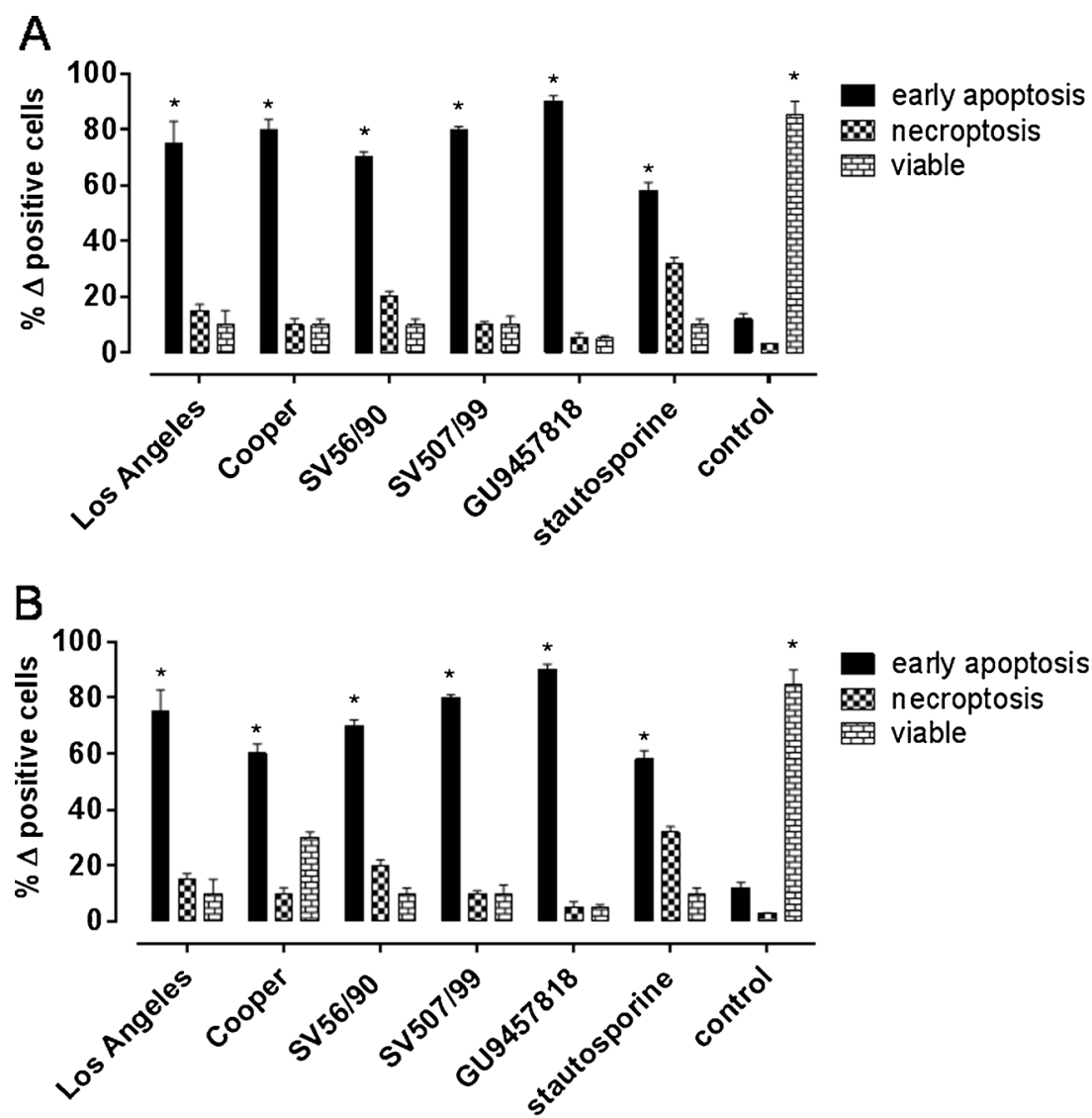

fact, BHV establishes latent infection in sensory neurons and transcription from the latent-related gene is readily detected in neurons from calves and rabbits (Jones et al. 2011). The phenomenon of latency has not been described in transformed cells infected by BHV1 (Cuddington and Mossman 2014, 2015).

Neurons have a high-energy demand and require a high density of mitochondria. Oncolytic viruses selectively replicate in and kill tumor cells while sparing normal cells. This ability is either natural (wild type) or may be induced through genetic manipulation (Cuddington and Mossman 2015). Although human viruses have shown efficacy as oncolytic agents in clinical trials (Pol et al. 2014), pre-existing immunity presents a barrier to systemic delivery and metastasis treatment. In this respect, a screen on BHV1 replication and cytotoxicity in a panel of human tumor cells revealed $72 \%$ of these cells being permissive to virus infection (Cuddington and Mossman 2014). It is known that mutations on KRAS (rat sarcoma superfamily oncogene that includes KirstenKRAS) are associated with lung, colon, and prostate tumor types and have been shown to interfere in tumor progression and treatment (Cuddington and Mossman 2014). There are various forms of cell death, which are classified by several morphological and functional criteria (Elmore 2007; Gonzalez-Dosal et al. 2012). In fact, necroptosis is induced through kinase activity (Silke et al. 2015). Notably, in this
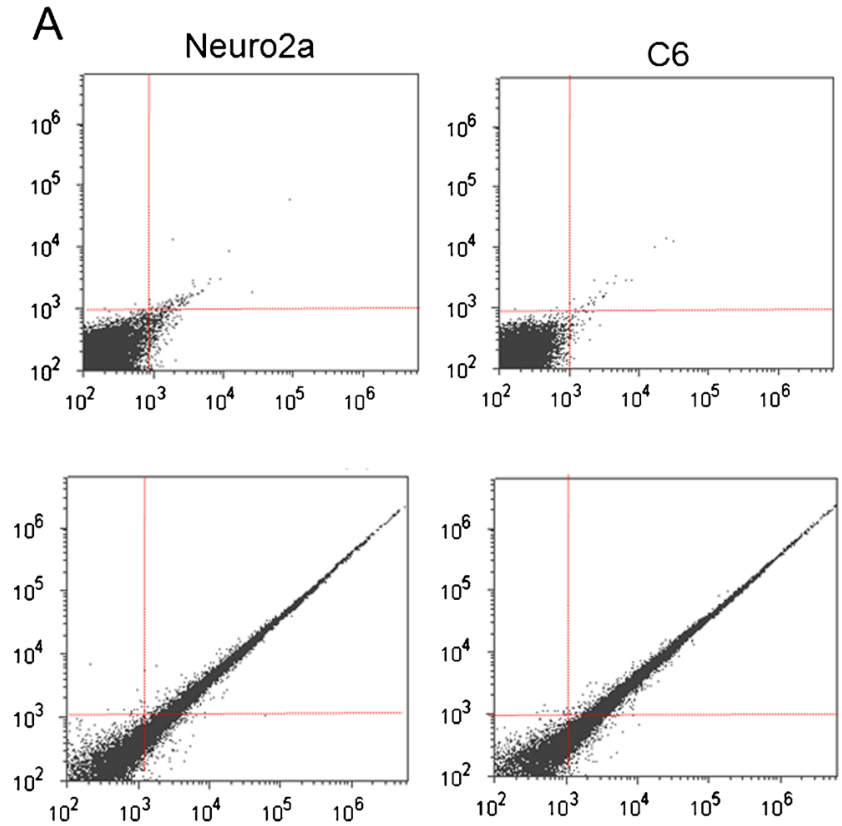

Fig. 4 Detection of ROS production in Neuro2a and C6 cells infected with BHV1 and BHV5 strains (a) and respective controls, uninfected (upper graphs) and treated $\mathrm{CO}_{2}$ atmosphere (lower graphs); (b) by flow cytometry analysis. The data is illustrated by dot plot graphic whereas $x$ axis corresponds to linear amplified ROS fluorescence and $y$-axis logarithmic ROS fluorescence. The fluorescence emission was acquired by BL3A filter excluding auto-fluorescence by global compensation tool $\left(>10^{3}\right)$, continuous line using Attune $\mathrm{TM}^{\mathrm{TM}}$ acoustic focusing cytometer 

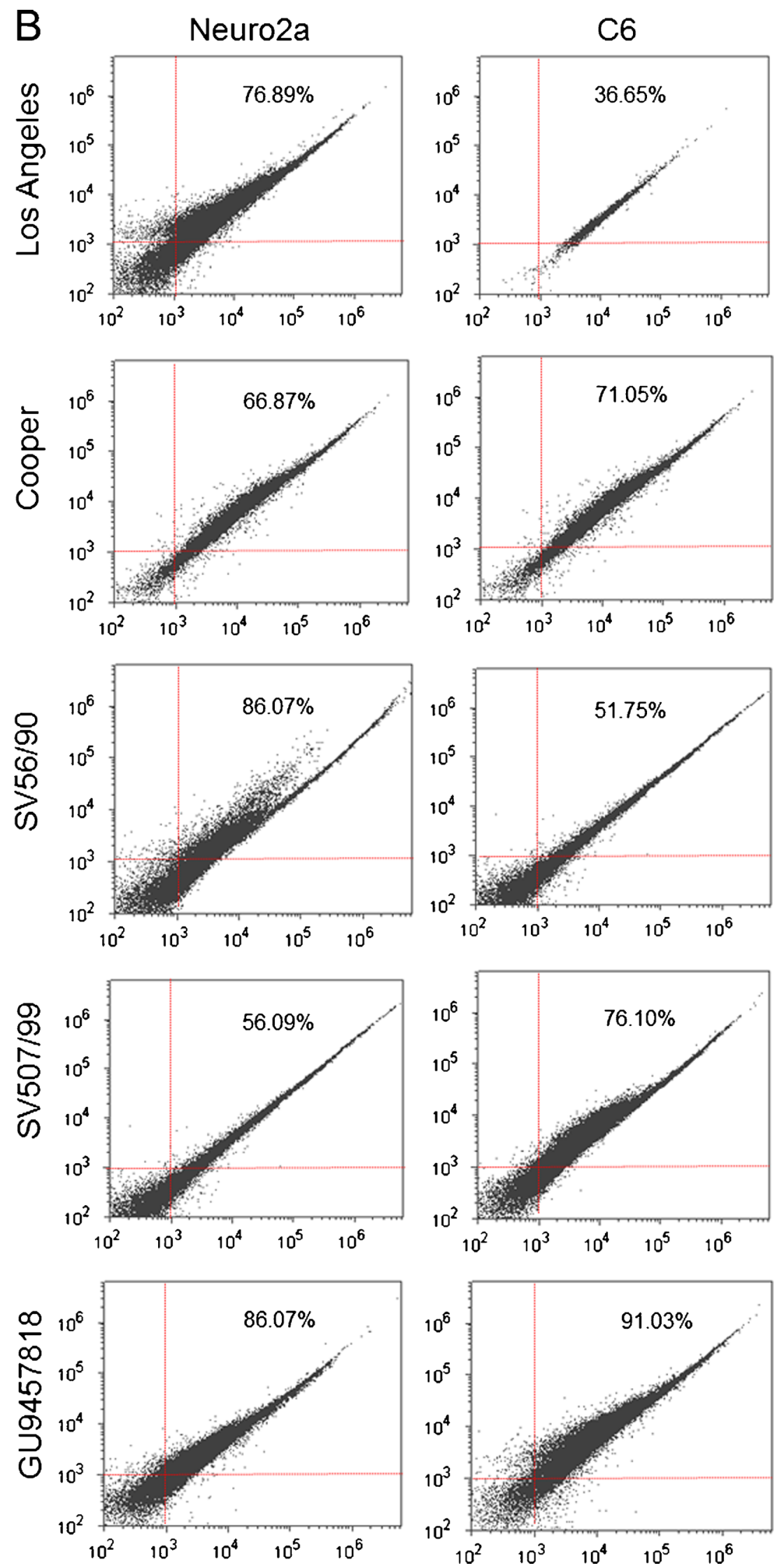

Fig. 4 (continued) 
Fig. 5 Acoustic focusing cytometer analysis performed to measure JC-1 emission at $48 \mathrm{~h}$ p.i. a Neuro2a-infected cells and b C6-infected cells. The data were obtained from four different experiments and processed using Attune acoustic focusing cytometer, and results were presented as \% JC-1-positive cells $(p<0.005)$

\section{A}

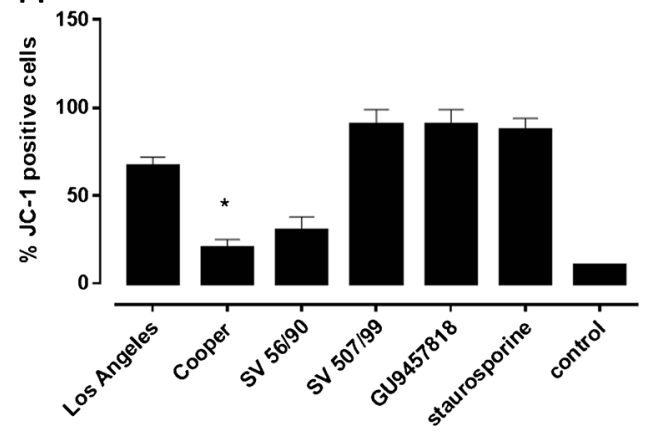

B

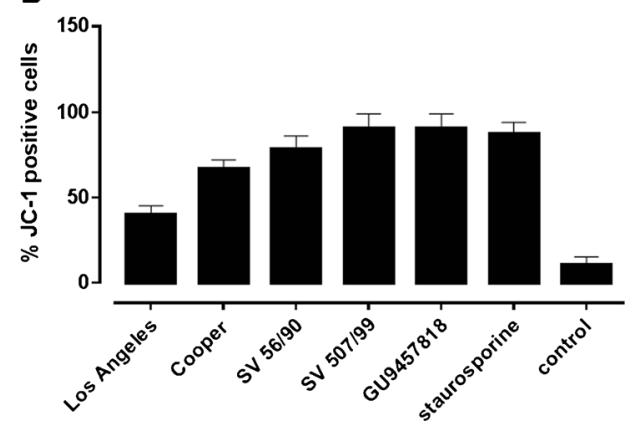

study, necroptosis seemed to be the preferred pathway of tumor cells observed by inhibition of kinase activity. In this study, however, ROS production seemed to be independent of Neuro2a and C6 apoptosis or necroptosis after BHV1 and BHV5 infection. The method by which BHV1 elicits death in human tumor cells is unknown. At least in this study, infected Neuro2a and C6 cells by BHV1 and 5 strains displayed high production of ROS, TNFA high expression, and levels of apoptosis and necroptosis. A previous study has shown that transient blockage of TNF alpha-blocking antibodies significantly enhanced virus replication and survival in glioblastoma intracranial tumors (Meisen et al. 2015). However, BHV1 and varicella-Zooster virus induce cell death, depending on the cell type (Geiser et al. 2008). In a recent study, BHV1 (Colorado strain) infection of a non-tumoral epithelial cell line induced an increase of cellular ROS and directly interfered in mitochondrial metabolism (Zhu et al. 2016).

It is known that neurons have a high-energy demand and require a high density of mitochondria (Englezou et al. 2012; Hood et al. 2003; Kulahava et al. 2010; Schachtele et al.
Fig. 6 Correlation between TNFA and BHV1 and 5 Glyco-C gene expression in Neuro2a cells infected by BHV strains at $48 \mathrm{~h}$ p.i. in five different experiments. The correlation coefficient $(r)$ was calculated according to the Spearman analysis and $p<0.005$ was considered significant
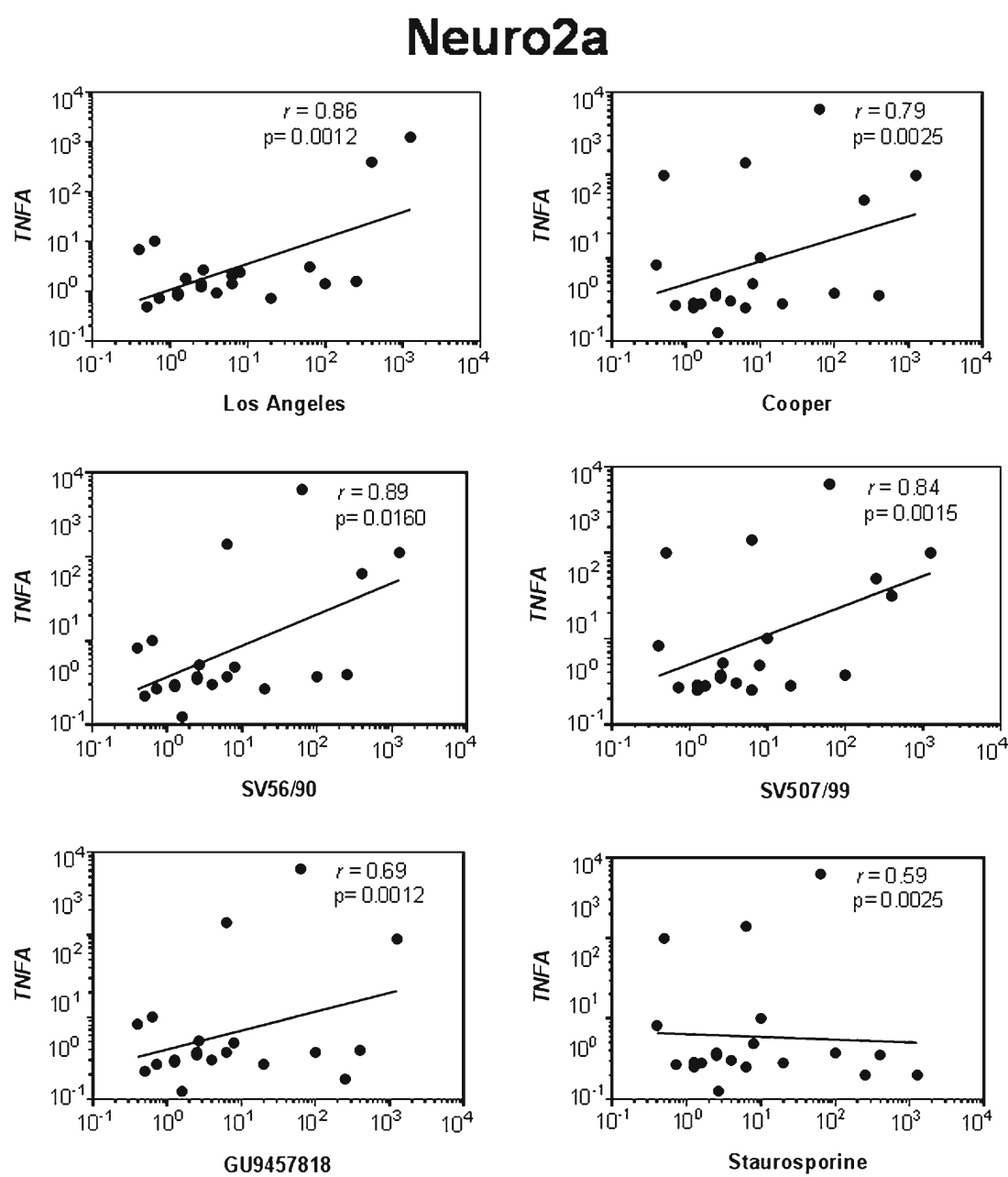
Fig. 7 Correlation between TNFA and BHV1 and 5 Glyco-C gene expression in $\mathrm{C} 6$ cells infected by BHV strains at $48 \mathrm{~h}$ p.i. in five different experiments. The correlation coefficient $(r)$ was calculated according to the Spearman analysis and $p<0.005$ was considered significant
C6
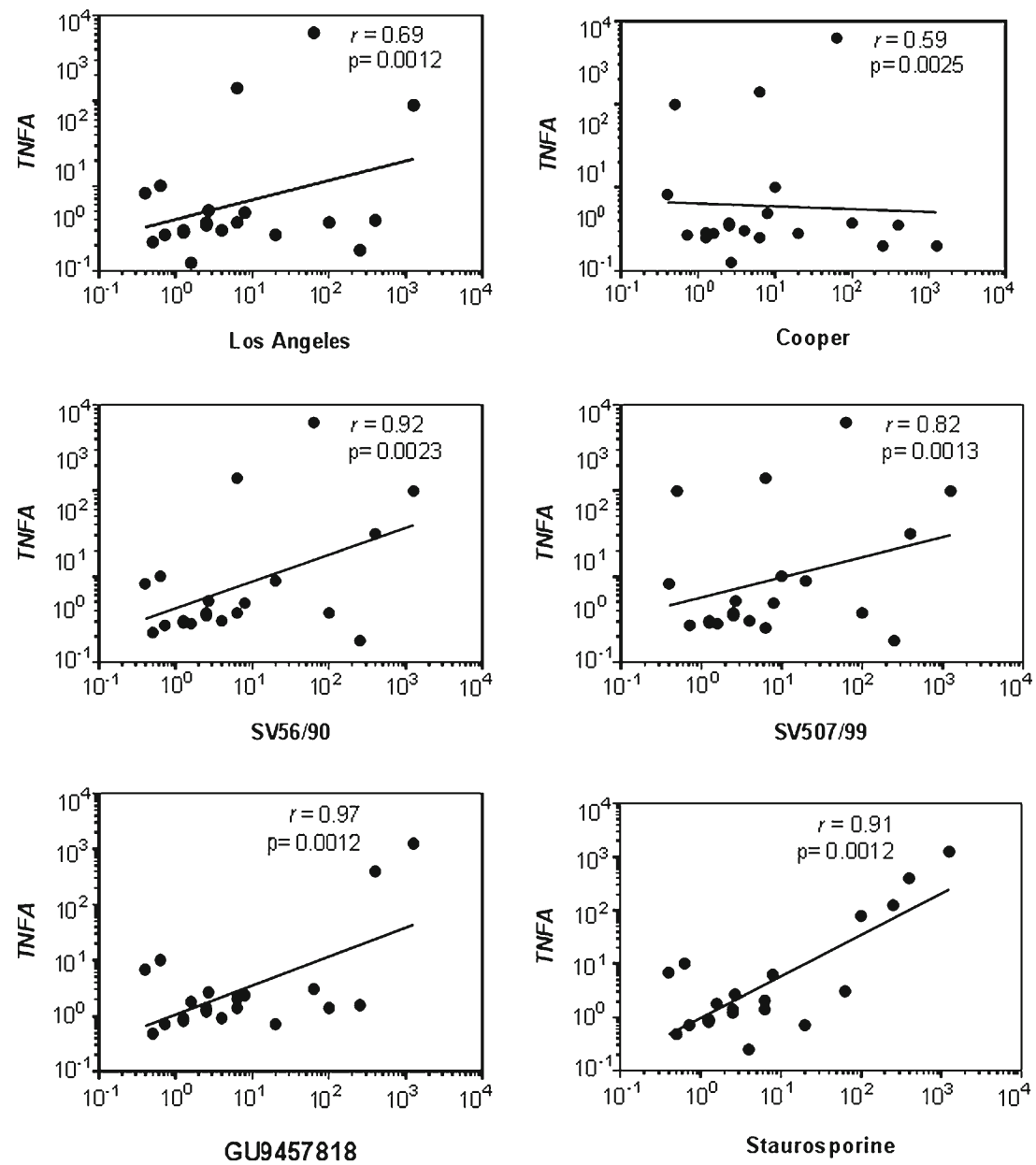

2010). In fact, Neuro2a cells have been described as a model of neuronal death studies upon infection with varicella-zoster virus (Christensen et al. 2011), equid herpesvirus 1 (Cymerys et al. 2012), and caprine herpesvirus 1 (Montagnaro et al. 2013). All these studies revealed susceptibility of neuronal tumor cells to animal alphaherpesviruses and their deleterious effects. However, to our knowledge, only BHV1 and EHV1 have been mentioned as potential oncolytic viruses for cancer therapy up to date (Cuddington and Mossman 2014, 2015; Courchesne et al. 2011).

Most of the time, mitochondrial dysfunction induces ROS generation associated with oxidative stress (Dashzeveg and Yoshida 2015; Englezou et al. 2012; Gonzalez-Dosal et al. 2012; Kulahava et al. 2010; Ohta and Nishiyama 2011; Schachtele et al. 2010; Scott 2010; West et al. 2011). In this study, mitochondrial membrane potential was also increased in BHV-infected cells. In fact, mitochondrial membrane potential is essential for cellular ATP production and increase ROS production (Englezou et al. 2012; Schachtele et al. 2010). Rabies virus, a neurotropic virus that infects human and animals, has been incriminated to induce neuronal death by ROS formation (Alandijany et al. 2013). Previous studies revealed that mitochondrial membrane potential can be altered without affecting non-transformed cellular cycle after infected by BHV5 (Brenner et al. 2012; Garcia et al. 2013). The expression of anti-oxidant protein-like 1 (AOP-1), a protective pathway, has been detected in bovine embryos and brain histological sections, both infected by BHV5 (Brenner et al. 2012; Cardoso et al. 2010). Furthermore, increase of mitochondrial membrane potential could be associated to virus replication and not always associated to cell death (Hay and Kannourakis 2002). Recent studies have shown the benefit of manipulating oncolytic viruses with therapeutic genes. Generating a safer potent oncolytic HSV-1 (human simplex herpesvirus) may be an alternative to treat human cancer (Miao et al. 2014).

The results described here strongly suggest that mitochondrial dysfunction is an important cause of oxidative stress in neuronal and glial tumor cells infected by BHV1 and BHV5 at different levels. Moreover, further investigations are required to support this hypothesis. 
Acknowledgments This work was supported by Fundação de Amparo à Pesquisa do Estado de São Paulo (Grant 2012/16715-4). T.C. Cardoso and E.F. Flores are recipients of $\mathrm{CNPq}$ (Brazilian Council for Research) funding. C Silva-Frade and A C G Rosa received fellowship from CNPq (Grant 500063/2014-1).

\section{Compliance with ethical standards}

Conflict of interest The authors declare that they have no conflict of interest

\section{References}

Alandijany T, Kammouni W, Chowdhury SKR, Fernyhough P, Jackson AC (2013) Mitochondrial dysfunction in rabies virus infection of neurons. J Neurovirol 1:537-549

Brenner MPC, Silva-Frade C, Ferrarezi MC, Garcia AF, Flores EF, Cardoso TC (2012) Evaluation of developmental changes in bovine in vitro produced embryos following exposure to bovine herpesvirus 5. Rep Biol Endrocrinol 10:53

Cardoso TC, Ferrari HF, Garcia AF, Bregano LC, Andrade AL, Nogueira AHC (2010) Immunohistochemical approach to the pathogenesis of clinical cases of Bovine Herpesvirus type 5 infection. Diagnostic Pathol 5:57

Cardoso TC, Novais JB, Antello TF, Silva-Frade C, Ferrarezi MC, Ferrari HF, Gameiro R, Flores EF (2012) Susceptibility of neuron-like cells derived from bovine Wharton's jelly to bovine herpesvirus type 5 infections. BMC Vet Res 8:242

Cardoso TC, Silva-Frade C, Táparo CV, Okamura LH, Flores EF (2013) Validation of a reference control for an SYBR-Green fluorescence assay-based real-time PCR for detection of bovine herpesvirus 5 in experimentally exposed bovine embryos. Mol Cell Probes 27:237-242

Cardoso TC, Ferreira HL, Okamura LH, Oliveira BR, Rosa AC, Gameiro R, Flores EF (2015) Comparative analysis of the replication of bovine herpesvirus 1 (BHV1) and BHV5 in bovine-derived neuronlike cells. Arch Virol 160:2683-2691

Christensen J, Steain M, Slobedman B, Abendroth A (2011) Differentiated neuroblastoma cells provide a highly efficient model for studies of productive varicella-Zoster virus infection of neuronal cells. J Virol 85:8436-8442

Courchesne MJ, White MC, Stanfield BA, Frampton AR Jr (2011) Equine herpesvirus type 1-mediated oncolysis of human glioblastoma multiforme cells. J Virol 86:2882-2886

Cuddington BP, Mossman K (2014) Permissiveness of human cancer cells to oncolytic bovine herpesvirus 1 is mediated in part by KRAS activity. J Virol 88:6885-6895

Cuddington BP, Mossman K (2015) Oncolytic bovine herpesvirus type 1 as a broad spectrum cancer therapeutic. Curr Opin Virol 13:11-16

Cymerys J, Slonska A, Godlewski MM, Golke A, Tucholska A, Chmielewska A, Banbura MW (2012) Apoptotic and necrotic changes in cultured murine neurons infected with equid herpesvirus 1. Acta Virol 56:39-48

Dashzeveg N, Yoshida K (2015) Cell death decision by p53 via control of mitochondrial membrane. Cancer Lett 367:108-112

Davison AJ (2010) Herpesvirus systematics. Vet Microbiol 143:52-69

Davison AJ, Eberle R, Ehlers B, Hayward GS, McGeoch DJ, Minson AC, Pellet PE, Roizman B, Studdert MJ, Thiry E (2009) The order Herpesvirales. Arch Virol 154:171-177

Del Médico Zajac MP, Ladelfa MF, Kotsias F, Muylkens B, Thiry J, Thiry E, Romera SA (2010) Biology of bovine herpesvirus 5. Vet J 184: $138-145$
Delhon GA, González MJ, Murcia PR (2002) Susceptibility of sensory neurons to apoptosis following infection by bovine herpesvirus type 1. J Gen Virol 83:2257-2267

Delhon G, Moraes MP, Lu Z, Afonso CL, Flores EF, Weiblen R, Kutish GF, Rock DL (2003) Genome of bovine herpesvirus 5. J Virol 77: 10339-10347

Dezengrini R, Weiss M, Torres FD, Oliveira MS, Furian F, Mello CF, Weiblen R, Flores EF (2009) Bovine herpesvirus 5 induces an overproduction of nitric oxide in the brain of rabbits that correlates with virus dissemination and precedes the development of neurological signs. J Neurovirol 15:153-163

Diallo IS, Corney BG, Rodwell BJ (2011) Detection and differentiation of bovine herpesvirus 1 and 5 using multiplex real-time polymerase chain reaction. J Virol Meth 175:46-52

Egan KP, Wu S, Wigdahl JSR (2013) Immunological control of herpes simplex virus infections. J Neurovirol 19:328-345

Elmore S (2007) Apoptosis: a review of programmed cell death. Toxicol Pathol 35:495-516

Englezou PC, Esposti D, Wiberg M, Reid AJ, Terrenghi G (2012) Mitochondrial involvement in sensory neuronal cells death and survival. Exp Brain Res 221:357-367

Ferrari HF, Luvizotto MCR, Rahal P, Cardoso TC (2007) Detection of bovine herpesvirus type 5 in formalin-fixed, paraffin-embedded bovine brain by PCR: a useful adjunct to conventional tissue based diagnostic test of bovine encephalitis. J Virol Meth 143:335-340

Garcia AF, Novais JB, Antello TF, Silva-Frade C, Ferrarezi MC, Flores EF, Cardoso TC (2013) Bovine herpesvirus type 5 infection regulates Bax/BCL-2 ratio. Gen Mol Res 12:3897-3904

Geiser V, Rose S, Jones C (2008) Bovine herpesvirus 1 induces cell death by a cell-type-dependent fashion. Microb Pathog 44:459-466

Gonzalez-Dosal R, Horan KA, Paludan SR (2012) Mitochondria-derived reactive oxygen species negatively regulates immune innate signaling pathways triggered by a DNA virus, but not by an RNA virus. Biochm Biophy Res Commu 418:806-810

Griffin BD, Verweij MC, Wiertz EJHJ (2010) Herpesvirus and immunity: art of invasion. Vet Microbiol 143:89-100

Hay S, Kannourakis G (2002) A time to kill: viral manipulation of the cell death program. J Gen Virol 83:1547-1564

Hood C, Cunningham AI, Sloberdman B, Boadle RA, Abendroth A (2003) Varicella-zooster virus-infected human sensory neurons are resistant to apoptosis, yet human foreskin fibroblasts are susceptible: evidence for cell-type-specific apoptotic response. J Virol 77: 12852-12864

Jones C, Silva LF, Sinani D (2011) Regulation of the latency-reactivation cycle by products encoded by bovine herpesvirus 1 (BHV-1) latency-related gene. J Neurol 17:535-545

Kulahava T, Semenkova GN, Kyacheva ZB, Krol W, Szliszka E, Grzbowski A, Czuba ZP, Cherenkevich SN (2010) Modification of redox processes in astroglial cells induced by microbial and viral infections. Med Sci Monit 16:11-17

Ladelfa MF, Kotsias F, Del Médico Zajac MP, Van den Broeke C, Favoreel H, Romera SA, Calamante G (2013) Effect of the US3 protein of bovine herpesvirus 5 on the actin cytoskeleton and apoptosis. Vet Microbiol 153:361-366

Meisen WH, Wholeb ES, Jaime-ramirez AC, Bolyard C, Yoo J, Russel L, Hardcastle J, Dubin S, Muili K, Yu J, Caligiuri M, Godbout J, Kaur B (2015) The impact of macrophage-and microglia-secreted TNF $\alpha$ on oncolytic HSV1 therapy in the glioblastoma tumor microenvironment. Clin Cancer Res 21:3274-3285

Miao L, Fraefel C, Sia KC, Newman JP, Mohamed-Bashir SA, Nq WH (2014) The potential application of a transcriptionally regulated oncolytic herpes simplex virus for human cancer therapy. Br J Cancer 110:94-106

Montagnaro S, Ciarcia R, De Martinis C, Pacilio C, Sasso S, Puzio MV, De Angelis M, Pagnini U, Boffo S, Kenez I, Iovanne G, Giordano A 
(2013) Modulation of apoptosis by caprine herpesvirus 1 infection in a neuronal cell line. J Cell Biochem 114:2809-2822

Ohnishi S, Ma N, Thanan R, Pinlaor S, Hammam O, Murata M, Kawanishi S (2013) DNA damage in inflammation-related carcinogenesis and cancer stem cells. Oxid Med Cell Longev 2013:387014

Ohta A, Nishiyama Y (2011) Mitochondria and viruses. Mitochondrion $11: 1-12$

Oldoni I, Weiblen R, Inkelmann MA, Flores EF (2004) Production and characterization of monoclonal antibodies to a Brazilian bovine herpesvirus type 5. Braz J Med Biol Res 37:213-221

Pol J, Bloy N, Orbist F, Eggermont A, Galon J, Herve Fridman W, Cremer I, Zitvogel L, Kroemer G, Galluzzi L (2014) Trial watch: DNA vaccines for cancer therapy. Oncoimmunol 3:e28185

Probert L (2015) TNF and its receptors in the CNS: the essential, the desirable and the deleterious effects. Neuroscience 302:2-22

Schachtele SJ, Hu S, Little MR, Lokensgard JR (2010) Herpes simplex virus induces neural oxidative damage via microglial cell Toll-Like receptor 2. J Neuroinflammation 7:35

Scott I (2010) The role of mitochondria in the mammalian antiviral defense system. Mitochondrion 10:316-320
Silke J, Rickard JA, Gerlic M (2015) The diverse role of RIP kinases in necroptosis and inflammation. Nat Immunol 16:689-697

Silva-Frade C, Gameiro R, Martins A Jr, Cardoso TC (2010) Apoptotic and developmental effects of bovine herpesvirus type-5 infection on in vitro-produced bovine embryos. Theriogenology 74:1296-1303

Silva-Frade C, Gameiro R, Okamura LH, Flores EF, Cardoso TC (2014) Programmed cell death-associated gene transcripts in bovine embryos exposed to bovine herpesvirus type 5. Mol Cell Probes 28:113-117

Varela APM, Holz CL, Cibulski SP, Teixeira TF, Antunes DA, Franco AC, Roehe LR, Oliveira MT, Campos FS, Dezen D, Cenci D, Brito WD, Rohe PM (2010) Neutralizing antibodies to bovine herpesvirus types $1(\mathrm{BoHV}-1)$ and 5 (BoHV-5) and its subtypes. Vet Microbiol 142:254-260

Weiblen R, Kreutz LC, Canabarro TF, Schuch LF, Rebelatto MC (1992) Isolation of bovine herpesvirus 1 from preputial swabs and semen of bulls with baknoposthitis. J Vet Diag Inves 4:341-343

West AP, Shadel GS, Ghosh S (2011) Mitochondria in innate immune responses. Nature Rev 11:389-402

Zhu L, Yuan C, Zhang D, Ma Y, Ding X, Zhu G (2016) BHV1 induced oxidative stress contributes to mitochondrial dysfunction in MDBK cells. Vet Res 47:47 